\title{
A PRESENÇA DE RÉPTEIS PAREIASSAUROS NOS SEDIMENTOS PERMIANOS DO RIO GRANDE DO SUL
}

Dina Celeste Araújo-Barberena (IG/UFRGS)

Numa expedição de verão, em 1979, realizada pelo setor de Paleovertebrados do Instituto de Geociências da UFRGS foram coletados restos de répteis pareiassauros na Formação Rio do Rasto, no Sudoeste do Rio Grande do Sul. Os fósseis foram coletados em 2 aflo ramentos na BR 153 (Rodovia Bagé/Aceguá). Num afloramento achou-se um crânio, um conjunto escápula-coracóide, um úmero e uma pélvis classificada, postericrmente, como pertencente a uma forma jóvem. No 2\% afloramento foi coletado um esqueleto axial, associado com a pélvis e parte dos membros anterior e posterior direitos.

Estas peças, diferentemente da permineralização da conhecida paleofauna da Formação Santa Maria, tem uma coloração cinza-escuro, decorrente da precipitação de compostos de manganês. o conjunto de fósseis demonstra uma precária preservação, devido a ação negativa de dois principais fatores: sua friabilidade e a presença de taxas de compressão bastante altas, acarretando, respectivamente, fraturamento e distorções.

- Na preparação em laboratório houve a necessidade de se utilizar novas técnicas e, até certo ponto, de cunho experimental, já que o material constitui o primeiro achado de paleotetrápodos neste nivel estratigráfico, no Rio Grande do Sul. Das peças coletadas, sem dúvida, o crânio foi o mais atingido durante sua diagênese, pois achava-se altamente comprimido, de forma que suas paredes laterais encontravam-se coladas uma à outra. Ao processo de preparação desta peça associou-se sua reconstituição, na tentativa de montá-la, buscando uma condição de arquitetura craniana o mais próximo da original e permitir seu exame tridimensional conforme fig. 1.

o estudo destes fósseis vem sendo publicado numa série de tra balhos (ARAÚJO, 1984a e b; 1985a e b; 1986a e b; 1987 e 1989a e b) e, no presente nos restringiremos a uma sintese das principais con clusões obtidas sobre estes registros fossiliferos. Como este material marca a primeira ocorrência deste grupo de répteis em conti 
nente americano, é nossa intenção contribuir com os colegas que, pe la ausência de material comparativo, não se acham suficientemente familiarizados com este grupo.

Através do estudo osteológico determinamos os fósseis como per tencentes ao gênero Pareiasaurus (Pareiasauridae, Pareiasauroidea) (Fig. 1).

Com base em coletas efetuadas em sedimentos permianos sul-afri canos, várias espécies foram descritas para o gênero pareiasaurus. BOONSTRA e KITCHING, respectivamente 1969 e 1970, consideraram-as em sinonímia a pareiasaurus serridens (primeira espécie estabelec $\underline{i}$ da no gênero por OWEN em 1876).

Da comparação morfológica e osteológica entre Pareiasaurus ser ridens e o material brasileiro observou-se uma série de diferenças, que caracterizaram o estabelecimento de uma nova espécie, por nós denominada de P. americanus (Fig. 1).

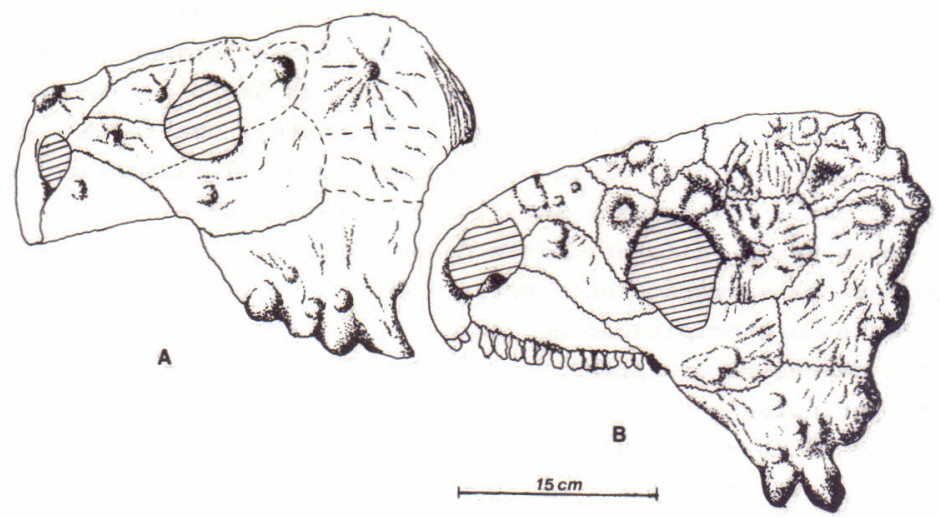

Figura 1. Vista lateral do crânio de Pareiasaurus serridens (A) do. Museu Geolögico de Universidade de Stellenbosh; Pareiasaurus americanus (B) da coleção de Paleovertebra dos da Universidade Federal do Rio Grande do Sul. Em escala aproximada, A, redesenhado de Boonstra,1934.

Na comparação das dimensões de pareiassauros apresentadas por autores precedentes com as medidas obtidas em $P$. americanus correlacionam, esta espécie às,formas achadas nas zonas cistecephalus e Daptocephalus. Com exceção do gênero Brachypareia, os pareiassauros coletados na Zona Tapinocephalus são comparativamente de tamanhos maiores.

Os afloramentos com P. americanus, foram cronocorrelacionados à Biozona Daptocephalus, topo da Série Beaufort Inferior e, datadas 
no Tartariano Médio a Superior e geocronologicamente mais jóvens do que os sedimentos do Membro Morro Pelado da Serra do Cadeado, Para ná, onde foi descrito Endothiodon, correlacionados à zona Cistecephalus por BARBERENA E DAEMON (1974), BARBERENA E ARAUJO (1975), BARBERENA, CORREA E AUMOND (1980).

A presença de pareiassauros na Formação Rio do Rasto indica que o paleo-ambiente reunia condições para a vida e deslocamento destes répteis pesados e de grande porte. O ambiente deposicional desta facies foi considerado como fluvial a lacustre. As caracteristicas taxonônicas do material indicaram que a ação de transporte, quando presente, fez-se à curta distância.

A existência de um estoque ancestral imediatamente pré-zona Tapinocephalus, na série Ecca Superior, é considerada como questão aberta, em virtude de aspectos ainda contraditórios dos trabalhos dedicados a este problema. Adotou-se o ponto de vista de que o estoque ancestral das paleofaunas reptilianas da Série Beaufort Infe rior (com implicação em sequências equivalentes) foi produto da sub divisão de uma biota ancestral nórdica.

No entanto, não parece seguro afirmar que tal estoque tenha iniciado sua radiação evolutiva precisamente à época imediatamente pré-Zona Tapinocephalus. É provável que os gradientes de temperatu ra, decorrentes do movimento das placas e importantes agentes de dispersão das paleofaunas, transgridam limites de tempo,rigidamente estabelecidos.

De forma geral, observou-se que, do Permiano Inferior ao supe rior, acontecimentos distintos paleogeográficos, incidiram na dispersão dos paleotetrápodos para os diversos continentes. Muito pro vavelmente, temperaturas progressivamente mais elevadas no hemisfério sul foram fatores de mảxima importância para dispersão, em direção sul, de grupos ectotérmicos como anfíbios e rêpteis.

Em função dos acima citados eventos paleogeográficos e paleoclimáticos, é provável que se tenha efetuado inicialmente uma dispersão para o sul de tetrápodos pré-zona Tapinocephalus mas, com pouca probabilidade de estabelecer rigorosamente a época em que tal fato ocorreu. Deste estoque ancestral ter-se-iam originado e desen volvido os elementos da Zona Tapinocephalus propriamente dita. Por outro lado, as evidências mostram que, à época da zona cistocephalus, a dispersão, a partir da Bacia do Karoo, teve sentidos leste e oeste; à época da Zona Daptocephalus, em virtude da existência da barreira representada pelo Mar Kenya, a dispersão efetuou-se para oeste e também para o norte, favorecida por climas mais quentes. 
REFERENCIAS BIBLIOGRĀFICAS

ARAOUJO, D.C. 1984a. Sistemática e Taxonomia dos Pareiassaurios:His tórico e Perspectivas Atuais. Pesquisas, Instituto de Geociências, UFRGS, Porto Alegre, 16:227-49.

ARAUJO, D.C. 1984b. Dispersão Paleobiogeográfica dos Pareiassāurios no Transcorrer do Permiano. In: XXXIII CONGR. BRAS. GEOL., Rio de Janeiro. $2: 1038-46$.

ARAGJO, D.C. 1985a. Sobre Pareiasaurus americanus sp. nov. do Permiano Superior do Rio Grande do Sul, Brasil. I - Diagnose Especifica. Ann. Ac. Bras. Ci., Rio de Janeiro, 57(1):63-6.

ARÁ́JO, D.C. 1985b. Estudo do Material Sul-americano de Pareiasauroidea. II - Descrição Osteológica do Crânio de Pareiasaurus americanus. Ann. Ac. Bras. Ci., Rio de Janeiro, 57(1):67-85.

ARAÚJO, D.C. 1986a. Estudo do Material Sul-americano de Pareiasauroidea. III - Descrição Osteolōgica da Escápula-Coracóide de Pareiasaurus americanus. Ann. Ac. Bras. Ci., Rio de Janeiro, 58 (3) : $381-7$.

ARAÚJO, D.C. 1986b. Estudo do Material Sul-americano de Pareiasauroidea. IV - Descrição Osteológica do Propódio e Epipódio dos Membros Anterior e Posterior de Pareiasaurus americanus. Ann. Ac. Bras. Ci., Rio de Janeiro, 58(3):389-403.

ARAÚJO-BARBERENA, D.C. 1987. Armadura osteodérmica de Pareiasaurus americanus Araújo, 1985 (Cotylosauria, Procolophonia, Pareiasau roidea) do Permiano Superior do Rio Grande do Sul, Brasil. PauZa-Coutiana, Série Geologia, Fund. Zoob. do R.G.S., Porto Alegre, no 1, D. 11-6.

ARAÓJO-BARBERENA, D.C. 1989a. Estudo do Material Sul-americano de Pareiasauroidea. V. - Descrição Osteológica da Pélvis de Pareia saurus americanus. Ann. Ac. Bras. Ci., R.J. 61(3):285-94

ARAUUJO-BARBERENA, D.C. 1989b. Estudo do Material Sul-americano de Pareiasauroidea. VI. - Descrição osteológica do Esqueleto Axial de Pareiasaurus americanus. Ann. Ac. Bras. Ci., Rio de Janeiro, $61(3): 295-309$.

BARBERENA, M.C. \& ARAUJo, D.C. 1975. Tetrápodes Fóssiles de Sudamé rica y Deriva Continental. In: CONG. ARGEN. PALEON. Y BIOESTRAT. 1, Tucumã, 1:497-504.

BARBERENA, M.C.; CORREIA, N.R. \& AUMOND, J. 1980. Contribuição a Estratigrafia e Bioestratigrafia do Grupo Passa Dois na Serra do Cadeado. Rev. Soe. Bras. Geoc. São Paulo, 10(4):268-75.

BARBERENA, M.C. \& DAEMON, R.F. 1974. A primeira ocorrência de Amphibia (Labyrinthodontia) na Formação Rio do Rasto, implicações geocronológicas e estratiqräficas. CONG. BRAS. GEOL. 28, Porto Alegre, Anais... 2:251-61. 
BOONSTRA, L.D. 1934. Pareiasaurian Studies. Part IX. The Cranial Osteology. Annals of the South African Museum, Cape Town, 31 : $1-3 \varepsilon$.

BOONSTRA, L.D. 1969. Fauna of the Tapinocephalus Zone (Beaufort Beds of the Karool. Annals of the South African Museum, Cape Town, $56(1): 1-73$.

KITChING, J.W. 1970. A Short Review of the Beaufort Zoning in South Africa. In: GONDWANA SYMPOSIUM, 2., South Africa. Proceedings and Papers. International Union of Geological Sciences. Comission on Stratigraphy. Sub Comission on Gondwana Stratigraphy and Paleontology. p.309-12. 
